Article

\title{
Pre-Clerkship Medical Students' Experiences and Perspectives of System 1 and System 2 Thinking: A Qualitative Study
}

\author{
William Sanders (D) and Douglas McHugh *(D) \\ Frank H. Netter MD School of Medicine, Quinnipiac University, Hamden, CT 06518, USA; \\ william.sanders@quinnipiac.edu \\ * Correspondence: douglas.mchugh@quinnipiac.edu
}

check for

updates

Citation: Sanders, W.; McHugh, D Pre-Clerkship Medical Students' Experiences and Perspectives of System 1 and System 2 Thinking: A Qualitative Study. Educ. Sci. 2021, 11, 34. https://doi.org/10.3390/ educsci11020034

Received: 17 December 2020

Accepted: 18 January 2021

Published: 20 January 2021

Publisher's Note: MDPI stays neutral with regard to jurisdictional claims in published maps and institutional affiliations.

Copyright: (c) 2021 by the authors. Licensee MDPI, Basel, Switzerland. This article is an open access article distributed under the terms and conditions of the Creative Commons Attribution (CC BY) license (https:// creativecommons.org/licenses/by/ $4.0 /)$.

\begin{abstract}
Dual-process theories may be invoked to explain how physicians interact with, interpret, and draw inferences from clinical information. Stanovich and West's model articulates two kinds of thinking-intuitive-based System 1 and analytical-based System 2-which have been under-investigated with physicians in training. This qualitative study explored pre-clerkship medical students' retrospective perspectives and experiences of System 1 and System 2 thinking via 12 semi-structured interviews and abductive, progressive focusing. Participants identified patient interactions, clinical note writing, knowledge synthesis, problem list and differential diagnosis generation, evaluating evidence, and critical appraisal of literature as pre-clerkship opportunities to engage in System 1 or System 2 thinking. Six major themes emerged from analysis of participants' interview transcripts: cognitive processes, deliberate practice, learning environment: being alone or being together, stickiness factor, biases and heuristics, and prior experience of attaining competence. Participants valued the anticipated role that System 1 and System 2 thinking will play in their future practice, and experienced nascent, self-regulated development of these cognitive processes during the pre-clerkship phase of their education without formal feedback or coaching from clinician preceptors. Pre-clerkship curricula should further embrace low-stakes, incremental teaching on metacognition and continuous monitoring of knowledge processing as a key competency for physician learners.
\end{abstract}

Keywords: cognitive load; dual-process theory; heuristics; medical student; pre-clerkship; qualitative; self-regulation; System 1; System 2

\section{Introduction}

Clinical reasoning is a consequential competency routinely exercised by almost all physicians irrespective of their specialty [1]. Rencic et al. (2016) defined it as, " ... the cognitive and physical process by which a health care professional consciously and subconsciously interacts with the patient and environment to collect and interpret patient data, weigh the benefits and risks of actions, and understand patient preferences to determine a working diagnostic and therapeutic management plan whose purpose is to improve a patient's well-being." [2] This often conflicts with human use of heuristics to make judgements or reach decisions [3]. Heuristics are simple, efficient cognitive shortcuts to produce solutions that are often, but not always, good enough [4]. They align with the fast and intuitive mode of cognitive operations referred to as System 1 thinking in Stanovich and West's dual-process theory model; by comparison, System 2 thinking is slow and deliberative [5-7] (Figure 1). 

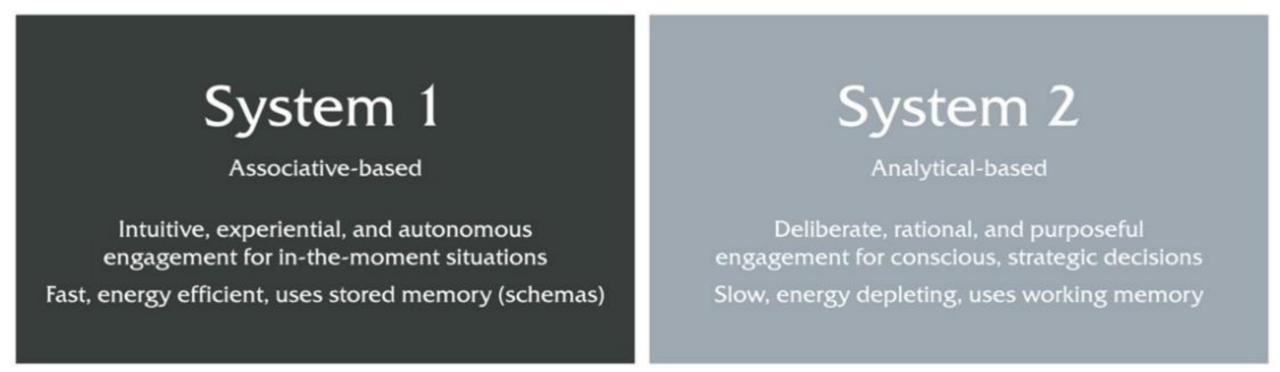

Figure 1. Brief comparison of System 1 versus System 2 thinking; adapted from Stanovich and West, 2000 [6].

System 1 is an effortless process that drives intuitive, heuristic thinking on the basis of pattern recognition and mental schemas (e.g., illness scripts, differential diagnosis algorithms) that have accumulated over time $[8,9]$. System 2 reasoning is slower and more effortful. It involves conscious reflection and deliberation with available data, and may prompt additional information seeking. Analysis of information and decision making is careful, rational, and systematic, and is necessarily dependent on working memory [10,11]. Consistent with this and the neurological basis of executive brain function, Rotgans et al. (2019) provided evidence, using function near-infrared spectroscopy and statistical parametric mapping analysis, that System 1 and System 2 processes produce differential activation of the cerebrum; System 2 thinking prompted greater activity in the prefrontal cortex [12]. System 2 is more often selected when outcomes are considered to be high stakes, when pertinent information is uncertain or interpreting its meaning is complex, and when time is not limited [13]. When problems are routine, under time constraint, or the decision maker is hungry, angry, or tired, System 1 kicks in [14]. Neither system is inherently inferior. With time, practice, and experience, cognitively demanding tasks become automatic (i.e., relocate from System 2 to System 1; see Croskerry 2009c for helpful illustration of System 1 and System 2 interactions in the context of patient presentation through diagnosis [11]) as slow, serial processing is replaced by pattern recognition and the fast, associative thinking that is authentic to expertise and proficiency. Unnecessary System 2 thinking costs time and expended mental effort; intuitive System 1 thinking is error prone when available data are unfamiliar, atypical, or ambiguous $[15,16]$. The propriety of physicians reasoning and making decisions using either System 1 or System 2 warrants consideration of the complexity and urgency of the prevailing clinical context and task, the physician's prior experience with similar circumstances and their outcomes, as well as their emotional state, and competence and self-confidence in their own metacognitive abilities [17]. To this end, the dual-process theory model holds that experts who possess adaptive mastery can transition readily to and from System 1 and System 2 thinking [1]. Quirk (2006) has stated, "Taken together, Systems 1 and 2 processing promotes greater efficiency in thinking, decision-making and action and help bring order to chaos and uncertainty." [18].

Little work has been devoted to exploring how medical students as a population of physicians in training experience System 1 and System 2 thinking and what meanings and interpretations they attach to it. Blumenthal-Barby and Krieger (2015) reported, from a critical review of 213 studies, that cognitive processing and heuristics have been underinvestigated in medical decision makers and are too reliant on hypothetical vignettes [19]. For instance, approximately $50 \%$ of 128 medical students did not changeover successfully to System 2 thinking when exposed to the three non-clinical, non-medical hypothetical vignettes that constitute the cognitive reflection test [17]. Instead, they made fast, intuitivebut wrong-answer choices.

Current and future providers need to be adept navigators and discriminating users of the increasingly ubiquitous health information that characterizes the 21st century. This should involve early and ongoing training with regard to rationality, thinking processes and metacognition. The pre-clerkship phase of the continuum of medical education is the 
bridge between experiences prior to medical school, specialty training that may follow, and future clinical practice. Understanding better how pre-clerkship physicians in training experience System 1 and System 2 thinking has implications for curricular design, selection of education strategies, and identification of mentoring, coaching, or formative feedback opportunities. The objective of this qualitative study was to explore medical students' perspectives and experiences of System 1 and System 2 thinking during the pre-clerkship phase of their undergraduate medical education, and in so doing answer: (1) to what extent are pre-clerkship students explicitly aware of System 1 and System 2 thinking, (2) what preclerkship opportunities exist for these cognitive operations, and (3) what are pre-clerkship students' experiences and perspectives of System 1 and System 2 thinking?

\section{Materials and Methods}

\subsection{Research Approach}

We adopted an abductive, progressive focusing approach to this investigation because progressive focusing permits qualitative findings to emerge from analysis of empirical phenomena and its interaction with theory [20]. Abductive reasoning complements this by making pragmatic inferences about data, while accommodating unexpected observations; it strives to match theory with reality and explain what is happening [21-23]. We performed 12 individual, semi-structured interviews with pre-clerkship medical students at the Frank H. Netter MD School of Medicine at Quinnipiac University (FHNSOM). Participant recruitment, interviews, and data analysis occurred from November 2018 to February 2019.

\subsection{Study Context}

The pre-clerkship stage of the FHNSOM curriculum consists of three courses: Foundations of Medicine (FOM), Clinical Arts and Sciences (CAS), and Scholarly Reflection and Concentration Capstone (SRCC). Basic and clinical science content is integrated across FOM, CAS, and SRCC, organized around organ systems blocks, and nested within multiple pedagogies focused on active learning, retention, and retrieval. The educational goal of FOM is to have pre-clerkship students gain foundational basic science knowledge, with an emphasis on detailed comprehension of common, representative medical illnesses. CAS includes extensive small group experiential learning with standardized patients, video review, goal setting, and clinician preceptor feedback. In addition, each first- and secondyear medical student is paired with a practicing community physician, and spends one day per week at either an internal medicine, pediatric, or family medicine site learning from their physician mentor (medical student home; MeSH). Under supervision, students are able to practice essential clinical skills with patients, including interviewing and examining patients, engaging in clinical reasoning skills and the diagnostic process, and assisting in creating treatment plans. SRCC focuses on students developing competence in evaluating information sources, critical appraisal of literature, interacting with and interpreting data, reflection, mentor-mentee relationships, responsible research practice, and capstone project scholarship.

\subsection{Recruitment}

Student participants were solicited in November 2018 via an announcement, posted to the FHNSOM second-year and first-year medical student Facebook groups, that asked about future interest in being interviewed. Responders were contacted via email by coinvestigator W.S. with information about the research team, the research objective, and a description of what participation in this study included. Participation was voluntary, with no academic consequences for decisions to decline or proceed to give informed consent and schedule an in-person interview with W.S. A total of 12 students ( 5 females, 7 males; 6 first-year and 6 second-year students) were selected through convenience sampling (i.e., timing of consent response and availability for interview). Participants were compensated 
with a $\$ 40$ Amazon gift card. Interviews ranged from 33 to $53 \mathrm{~min}$, with an average length of $44 \mathrm{~min}$.

\subsection{Data Collection}

One-on-one, in-person interviews were conducted by W.S. in study rooms on campus that ensured confidentiality. A semi-structured series of interview questions were developed to explore participants' pre-clerkship experiences of System 1 and System 2 thinking, and what meanings and interpretations they attach to them (Appendix B). Prior to each interview, all participants were provided with a one-page pre-interview guide describing how Stanovich and West's (2000) dual-process theory model defines System 1 and System 2 thinking and distinctive attributes of both cognitive processes (Appendix A; Figure A1) [6]. This was to invoke a shared nomenclature and conceptual understanding between investigators and participants. Questions that participants had after reading the pre-interview guide were responded to by W.S.; similar clarifications were given to reoccurring clarification questions. Participant responses were audio recorded, transcribed verbatim, and the individual transcripts shared with interviewees for accuracy verification (i.e., member checking). No suggested edits were received from participants. De-identified transcripts from initial interviews were read then assigned first-stage preliminary codes. Through progressive focusing, our semi-structured interview guide was revised iteratively, which permitted a more meaningful exploration of co-constructed themes. Medical students were recruited until we attained thematic saturation (i.e., the point at which observing more data will not lead to discovery of more information related to research questions).

\subsection{Reflexivity}

The investigative team comprised W.S., a second-year medical student; and D.M., a non-clinical associate professor with experience in qualitative methodology who led all stages of the research. Best practice standards acknowledge that qualitative data collection and analysis are influenced by investigators' perspectives, roles, and the circumstances or processes by which studies are conducted [24]. In order to increase trustworthiness, we sought to remain sensitive to this by keeping track of our actions in, and reactions to, the research situation [25]. W.S., as a peer or near-peer to the participants, conducted the interviews, kept reflexive notes, and sought to stay cognizant of his insider-outsider vantage point. D.M. is director of the SRCC course and brought his own outlook of System 1 and System 2 thinking from his participation in pre-clerkship curriculum design and delivery. D.M. did not interview any of the students given his status as a faculty member. D.M. and W.S. adopted a Husserlian approach by putting their own ideas in a reflexive diary and withheld explicit judgments, assumptions, and commentary during the interviewing phase in order to allow participants to describe their experiences without contamination [26].

\subsection{Data Analysis}

Transcripts were reviewed independently and coded provisionally by W.S. and D.M. Abductive coding combines inductive and deductive approaches [27]. Initial codes were derived from the preexisting framework of dual-process theory [6]. We analyzed the content of the interview transcripts to deduce patterns arising from the presence and absence of these initial codes. Further codes were constructed to capture unanticipated participants' observations and perspectives. These were derived inductively by constant comparison [28]. This approach allowed the main aspects of System 1 and System 2 thinking to be integral to the process while permitting the emergence of themes from our data sets. W.S. and D.M. then met together to group similar codes into categories and identify major concepts while referencing memos and field notes. Iteratively, major concepts were further organized and expressed as themes. NVivo 12 qualitative analysis software (QSR International Inc., Burlington, MA, USA) was used to facilitate these coding processes. The Quinnipiac University institutional review board approved this study (\#08818). 


\section{Results}

We recognized medical students as knowledgeable agents capable of representing and articulating the different aspects of how they interact with and make meaning from educational experiences that are directly perceptible to them illustrative quotes are identified by anonymous participant codes. Although not everyone was explicitly aware of Stanovich and West's model of dual-process theory, its terminology, or associated attributes before this study, our results indicated that participants were cognizant of intuitive-based and analytical-based thinking while in medical school and the value of their role in their future practice:

I don't think I would know about the names of these different thinking systems if it wasn't for your research project. I don't think we've specifically talked about dual process theory. I know we've talked about heuristics. Is that the right word? About problems with reasoning. I don't remember if that was in CAS or SRCC. But I know we've talked a lot about how doctors do a lot of this. We didn't say System 1. But a lot of this pattern recognition, quick judgment in diagnoses. And that the best physicians are the ones that can recognize that there's bias and there's problems with that thinking, and can use the more analytical, complete thought process. But we didn't really talk about how that's System 1 and System 2. (S12)

When asked to identify development opportunities that exist in the pre-clerkship phase for these cognitive operations, participants pointed to patient interactions, clinical note writing, knowledge synthesis, problem list and differential diagnosis generation, evaluating evidence, and critical appraisal of literature. In addition, six major themes emerged from our abductive analysis of interview transcripts: cognitive processes, deliberate practice, learning environment: being alone or being together, stickiness factor, biases and heuristics, and prior experience of attaining competence.

\subsection{Cognitive Processes}

Participants linked cognitive scaffolding to their developing System 1 thinking and System 2-to-1 transitions. Scaffolding strategies used intentionally by learners included visual scaffolding, clinical mnemonics, physical exam and history-taking checklists, talking it out loud, and whiteboard drawings. One student reflecting on learning new physical exam maneuvers said:

I read the student guide which ... it's a bit more effortful because it takes time to read ... but then I visualize what the guide is actually saying: how I would maneuver, or how I would perform this maneuver, how I would put it all together so it makes sense in a chronological order, when actually seeing a patient. Then I practice that on the standardized patient. Generating mental imagery helps me transition over time to a System 1 approach: where I'm moving the patient intuitively, I'm manipulating the abdomen, or performing independently what the student guide was stipulating. (S08)

Students also highlighted clarity and concrete information as being important when forming a network of linked concepts:

I need to know definitive facts about a subject. This is related to this, and this is always going to be related to this. That helps me make the connections clear in my mind to get that baseline of whatever kind of topic I'm thinking about. (SO2)

Others described situations where they rely on cognitive schemas to establish patterns of thought around organized categories of information, and the relationships between them, to develop awareness of pattern recognition dissonance relevant to patient care:

Okay, this person's going into septic shock. Okay, let me open up my brain file cabinet on septic shock and go through my normal processing of this. And then it's just having that ability and awareness ... again, which comes through time I think... that if there's a red flag that goes off, and it says, "Okay, this is abnormal. This is not what it is," that's when you need to be able to stop, slow down, switch over, and think logically, analytically. (S10) 


\subsection{Deliberate Practice}

Participants explained that to feel confident in their acquisition of novel information or abilities, and comfortable with their ability to recall or perform accurately, multiple repetitions over time were required. One student practiced physical movements to engrain knowledge and clinical skills relevant to patient interactions:

Only through repetition can you really establish System 1 ... You could read about how to apply EKG [electrocardiogram] leads, and you could know it off the top of your head. How to apply it to the exact locations and which leads go where. But you have to do it at some point. You're not going to get that muscle memory — that's what I kind of attribute to System 1-automatic, muscle memory. Because you're not going to get that until you actually physically do it and you repeat it a few times. (SO2)

Another student leveraged ANKI (https://apps.ankiweb.net; developer: Damian Elmes), software that supports spaced repetition learning, to pursue fast, automatic recall:

I use ANKI for [learning retrieval] repetition. I test myself. I ask myself questions with my ANKI cards and continue to do that. If I learn something new on Monday, by Friday I've seen that content tons of times. So when I go to weekly case review and faculty ask something - boom-I've seen this a hundred times, I've seen this so often that it clicks in my head. (S05)

\subsection{Learning Environment: Being Alone or Being Together}

There was a notable consensus among participants that knowledge synthesis involving System 2 learning, and subsequent movement towards System 1, improved if their initial exposure to new material occurred in a quiet, solitary environment:

Sketchy videos [informative, sketch-based learning videos; SketchyMedical, Sketch Group LLC] have helped me go from effortful, slow thinking about pharmacology and microbiology to very fast, intuitive thinking. But I don't like distractions. I can't watch the videos with anybody around. (S08)

Another student noted that despite their preference for slower, solitary learning it made gauging progress towards mastery difficult:

I tend to be more of a solitary learner, so I learn better when I just can focus and sit by myself and have my time with the material. Although I prefer learning on my own in a solitary way, it's sometimes hard to gauge whether I really understand the material or not. So then, when somebody mentions something that we learned that I don't have a clear grasp on, it becomes very apparent. (S09)

Learning activities that brought some students together too soon were met with resistance, frustration, and disengagement from opportunities to learn jointly (i.e., to take advantage of others' resources and skills). At FHNSOM, collaborative classroom events (CCs) involve eight students working as a team with the curricular goal of them experiencing learning convergence (i.e., when intellectual synthesis, consensus, and consolidation occurs through people interacting by shared experience and taking on asymmetric roles). These participants describe defaulting to slowly, effortfully learning alone while physically near other students in the context of this small group learning environment:

I think [collaborative classroom events] might be too fast paced for me. And I think it's the group setting. I'm not always comfortable raising my hand and asking questions or stopping. And also, our CCS often have a lot of material to get through, like a big long worksheet to get through in one hour. So we always end up splitting it up amongst our group like, I'll do whatever ... question four ... and I'll then I can learn how to answer question four, but I have no idea how to do any of the other questions on the paper. (S06)

"It's because I have not had enough time to consolidate the material and I'm trying to go directly to System 1, but I haven't had enough time to really develop it in my head. So I'm still on System 2 when we get to CC, and even then I can't perform that well on System 2 and that's where I'm at when I'm in CC. I'm still trying to figure things out, 
and we're moving so quickly trying to answer all the questions and explain it to people and I'm just like, "I haven't learned this yet." So I'm still in System 2 when we get to CC." (S05)

\subsection{Stickiness Factor}

Each participant described ways in which information had been presented transiently that had stuck with them, and months-to-years later allowed them to recall the information vividly, quickly, and effortlessly. S08 and S07 identified embarrassment as a salient stickiness trait that compelled them to pay close, sustained attention, and in turn accelerate System 1 learning. For others, personal experiences, stress/pressure, emotional connections, immediate feedback, and relationships of trust facilitated development of System 1.

S08 shared his experience with pimping; urban dictionary defines this as "the act of singling out one person from a group and testing their knowledge by asking a series of intense, difficult questions in front of everyone" [29]:

I get pimped quite often in MeSH. Sometimes I just don't know the answer, so I try to reason through possible answers. What type of therapy should we give this patient? Or what are underlying causes of presenting symptoms? My nervous system is going crazy because I don't know the answer immediately and its awkward silence, where I'm almost embarrassed. But afterwards I don't forget it. Once we talk it out together and it does make sense, I can make that connection again easily. (S08)

I feel like you remember things a lot more when you get them wrong and you were embarrassed in that moment. Whenever you see a case like it again, you're like, "Oh, my god I remember that one time I was super embarrassed because I got this wrong." Then you just spew out the answer when you are presenting because you remember automatically. (S07)

\subsection{Biases and Heuristics}

Heuristics align with System 1 thinking as a means to reduce cognitive load but can hinder learners from switching to System 2 when appropriate. Impeding heuristics implicit in participant's responses that we perceived to obstruct intersystem $1 \longleftrightarrow 2$ transitions (and their contexts in parentheses) were: anchoring (pattern recognition and previous experience of developing competence), representativeness (developing cognitive schemas), cognitive miser (group learning environments), and availability (stickiness factors). For example, S12 and S01 spoke of instances of the anchoring heuristic - the human tendency to base decisions on known 'anchors' or familiar positions-leading to errors with or an overreliance on pattern recognition:

I can give you a great example where I was wrong. My pattern recognition in our pulmonary embolism [problem-based learning] case. Looking through the EKG data, my mind immediately recognized what I thought was a pattern. I believed it was an inferior myocardial infarction. I didn't do a more detailed analysis of the EKG and really compare it well with the patient's presentation. I just kind of saw what I wanted to see to make it work with what I had quickly jumped to, the diagnosis in my head. (S12)

When I first see a patient ... mostly I think what's their chief concern? What's the thing that they want to prioritize in that visit? And then from there I create a list of differential diagnoses. Like ... there is always an issue or there is always the dilemma of ... okay ... how do I get out of my natural heuristic of immediately going to my familiar top diagnoses versus generating a long list of different things that I should consider? (S01)

\subsection{Prior Experience of Attaining Competence}

Some participants noted that they often utilized, or had the tendency to rely on, the system of thinking that they had the most previous experience with: 
I'm trying to use more of System 2 but I think that my default is System 1 ... I think my previous experience [as a paramedic] has given me some kind of a background of patterns to recognize ... I had to quickly treat a patient and I didn't necessarily have all of the time that I would like to reason through it. Our [paramedic] program emphasized reflexive, pattern recognition of presentation or vitals rather than understanding the pathology or why the patient looks like this or why I'm treating with this medicine or intervening through these actions. (S12)

Before medical school I worked in basic and translational research. That arena is very conducive for System 2 thinking. You're trying to answer a research question. You come up with a hypothesis and then you come up with how you're going to test out that hypothesis ... And the data analysis ... you have a lot of time to look at the data and sit with the data, consult with related literature, and think about what is this actually telling me?... So there's just a lot more room to do the System 2 kind of thinking. And it tends to be very ... you have to be very methodical. You have a protocol. If you're being very methodical and effortful and logical, then you tend to do a better job than if you do things too quickly in that setting. (S09)

\section{Discussion}

Clinical reasoning and decision making are cognitively complex skills that demand higher-level thinking from practicing health care professionals; skills they begin to acquire during medical school. van Merriënboer et al. (2006) have described cognitive tasks as those that involve an individual encoding newly obtained information or data such that it can be used proximally by working memory or organized into long-term memory structures for future retrieval and use [30]. Stanovich and West's dual-process theory model outlines an architecture for the cognitive interplay between intuitive System 1 and deliberate System 2 thinking. This qualitative study provides a contextualized glimpse into preclerkship medical students' perspectives and experiences with these cognitive processes. Learners, in the absence of relevant prior experience, associated new learning with effortful, cognitively demanding System 2 processes; whereas progress towards achieving accuracy, faster recall, increased automaticity, and decreased effort was associated with System 1 and mastery. Investing effort to sustain a high cognitive load over a period of time is burdensome and mentally fatiguing [31]. Thus medical students are well placed to seek effective strategies that allow them to pursue a System 2-to-1 trajectory.

\subsection{Intersection with Self-Regulated Learning and Cognitive Load Theory}

Increasing attention is being paid to self-regulated learning and cognitive load theory as frameworks relevant to various health education contexts [32-38]. Put simply, selfregulated learning concerns self-initiated and self-monitored activities, practices, and behaviors that learners engage in to pursue academic mastery [39]. Cognitive load theory concerns how working memory functions with respect to learning; it draws attention to the limited capacity of this cognitive system [40]. Using these frameworks moved our analysis beyond simple characterization of how System 1 and System 2 manifested for our participants towards identifying opportunities for educators to provide supportive feedback to help learners improve and refine their cognitive and metacognitive competence. When a student is presented with a learning task or problem, a necessary amount of mental effort is expended in order to meet the perceived standard expected of them. Sewell et al. (2019) write that cognitive load theory acknowledges some occupation of capacity-limited working memory must occur while learning, reasoning, or decision making given the intrinsic requirement to hold onto and mentally manipulate data or information for a prescribed amount of time; however, by reducing any extraneous burdens on working memory, we ease information processing and facilitate the attainment of desired outcomes [37]. Evidence-based approaches to reducing cognitive load and facilitating a transition from System 2 to 1 include cognitive scaffolding, maximizing the signal-to-noise ratio, and creating opportunities for collaborative learning [41]. When reflecting on their 
pre-clerkship educational experiences, our participants described their efforts to intentionally scaffold their own cognitive tasks through various self-selected strategies. Defined generally, scaffolding metaphorically refers to an opportunity in which an explicit activity or a more expert tutor acts as a scaffold (temporary structure), helping the learner to do things they cannot perform alone yet [8]. In analyzing cognitive task requirements and choosing, modifying, or creating strategies to scaffold their transition to System 1 thinking, our participants' actions are consistent with the metacognitive and strategic attributes of self-regulated learning [42-44]. They perceive and interpret their own thought processes and plan, monitor, evaluate, and reinforce personal progress. Self-regulated learning aims to render these self-selected strategies visible to the adult learner and eventually have them become automated. Making a concept concrete (i.e., removing unnecessary complexity or distraction and grounding an idea in sensory reality) is consistent with maximizing the signal-to-noise ratio: "I visualize what the guide is actually saying ... (S08)", "I need to know definitive facts ... That helps me make the connections clear in my mind. (S02)". Superfluous cognitive load hinders learning [41]. Cognitive load theory posits that solitary learning loses efficiency as task difficulty increases. Team- or group-based collaborative learning circumvents this by distributing cognitive processing over several learners; even when accounting for necessary information re-integration and synthesis [41,45]. This scheme is at odds with the stance taken by some of our participants with regard to collaborative classroom learning events at FHNSOM. For these students, learning activities that brought them together with others to learn jointly failed to reduce their cognitive load (invested mental effort) and facilitate System 2-to-1 transitions. There appears to be three factors associated with this: (1) rather than engaging in true collaborative learning, the group adopted a "divide and conquer" tactic that fostered learning alone while physically near other students; (2) learners perceived a need to spend more time alone engaged in slow, effortful System 2 processes; and (3) they did not consider the learning environment to be conducive to revealing to peers their need for help or asking the group to slow down. Self-regulated learning also embraces the learner's ability to understand and control their learning environment [42-44]. Our participants were unanimous in their preference for initial exposure and slower, methodical System 2 processing of new material to occur in a quiet, solitary environment. This is consistent with preferences and actions that optimize signal over noise, thereby reducing extraneous cognitive load. They were also aware of the potential limitation inherent to such a learning environment with respect to cross-referencing what is known and comprehended by others but not known and comprehended by self. Cognitive load theory treats schemas (organized, categories of knowledge held indefinitely) as the arrangement of mental constructs that constitute how we represent and store knowledge [40]. System 1 leverages schemas for fast processing. Novice learners have constructed and accumulated fewer schemas than advanced learners or experts. The schematic structures encoded in long-term memory are altered by learning activities. Sweller (1988) stated that this is paralleled by progress in performance proficiency from awkward, blundering, sedate, and arduous ... to straightforward, trouble-free, and easy as pattern matching and recognition become more efficient and automaticity emerges [40]. Participants in this study coupled their developing schemas to pattern recognition and their nascent ability to recognize when something falls out of a pattern, triggering a return to effortful, analytical System 2 processing. They also described salient stickiness traits that impacted meaningfully their schema structures to decrease the mental effort required for successful retrieval. Considerable amounts of deliberate practice are needed to develop expertise [11,15]. Deliberate practice may be thought of as self-initiated and self-monitored activities repeated regularly to firstly attain, then maintain or improve, proficiency. Therefore, self-regulated learning as an educational strategy is well placed to help individuals develop expertise and mastery through practice-based refinement [46]. Our participants described practicing the physical movements required for placing EKG leads on a patient, and their effective use of spaced repetition software to achieve System 1 capabilities. The selected strategies represent good, evidence-based choices. Issenberg et al. 
(2005) stated in a best evidence medical education (BEME) systematic review of simulation literature that "repetitive practice was a "primary factor in studies showing skills transferring to real patients'" [47]. It is also understood that repeated retrieval practice produces better knowledge retention in the long term, improves understanding of material to be learned, and facilitates its application to new contexts [48,49]. This aligns with Rosby et al. (2018)'s report and a subsequent commentary (Simpson et al. 2019) that System 1 pattern recognition could be induced in second year medical students after 15 min as a function of practice $[50,51]$.

\subsection{Heuristics}

Physicians make use of heuristics to guide their reasoning and clinical decisions about how to reduce anxiety, costs, and delays [52]. Heuristics align with System 1 thinking as a means to reduce cognitive load but can hinder learners from switching to System 2 when appropriate. We perceived susceptibility to four heuristics that were implied by our participants' responses. The anchoring heuristic manifests when people base decision making on perspectives they hold to which they are habituated or accustomed; they are "anchored" to these familiar positions [53]. It explicitly draws on initial impressions formed in connection with familiar information presented about a particular problem. Aragón (2017) writes that we "judge automatically data to be more important or probable if they are recent, vivid, readily available, or coherent; the converse is also true." [54] S12's prior experience as a paramedic anchored them to System 1 thinking and fast pattern recognition that produced an error in a pulmonary embolism problem-based learning case; and S01 mentioned, " ... immediately going to my familiar top diagnoses versus generating a long list of different things that I should consider." The representativeness heuristic is connected here with pre-clerkship students constructing cognitive schemas. This mental shortcut assesses whether a person or an event should be put into a certain category by judging how similar they or it is to the prototypical person or event of that category [55]. S10 describes searching their "... brain file cabinet on septic shock." This shortcut could either trigger or mask dissonance associated with a "... need to be able to stop, slow down, switch over, and think logically, analytically." Availability bias is the inclination for decisions to be heavily influenced by previous experiences that are recalled easier or more quickly [56]. This correlates with our participants' experience with stickiness traits impacting schemas. S07 and S08 found it effortless to retrieve quickly knowledge they had previously encountered in a context characterized by embarrassment. However, the most available information may not be the most germane. Lastly, the cognitive miser heuristic operates when we permit our problemsolving and thinking to be simple, less effortful in order to eschew sophisticated, higher order cognition that requires mental exertion [57]. As mentioned before, cognitive load theory suggests humans are frugal in wanting to expend as little cognitive demand as possible when faced with questions or problems. S06 told us of their collaborative learning group's "divide and conquer" tactics where problems or questions related to a progressive learning experience were piecemealed and delegated to smaller subgroups. This results in learners only partially querying their mastery of salient, interconnected content which, in turn, differentially impacts their cognitive schemas.

\subsection{Implications for Medical Education}

Our findings are notable for some students' (e.g., S07, S12) description of faulty reasoning and conclusion making attributable to their own System 1 thinking, and for the absence of students' mention of feedback and coaching with regard to their pre-clerkship experience of System 1 and System 2 processes-despite being recipients of weekly feedback from clinician preceptors in the CAS course at FHNSOM (confirmed by D.M.'s faculty insider vantage point). We believe this represents a missed opportunity for intentional or serendipitous learning of these cognitive processes to be nested within a competency-based pre-clerkship model characterized by helpful feedback and learner-centered coaching. Lefroy et al. (2015) defined helpful feedback as, "a supportive conversation that clarifies 
the trainee's awareness of their developing competencies, enhances their self-efficacy for making progress, challenges them to set objectives for improvement, and facilitates their development of strategies to enable that improvement to occur" [58]. Such feedback supports self-regulation by responding to learners' proactive seeking of formative commentary on the outcomes of their actions from sources external to themselves.

It is important for a physician to know when their fast, tacit, associative processing of a given clinical situation is appropriate and when it is not; to know when instead to access and more slowly, explicitly, and analytically consult then interpret available knowledge sources. Furthermore, pre-clerkship education is intended to, "initiate the process of clinical performance development and to prepare the student to be ready to participate in and optimally learn from the direct care of patients during the clerkship experience" [59]. Given these affirmations, we believe pre-clerkship curricula should further embrace lowstakes, incremental teaching on metacognition and continuous monitoring of knowledge processing as a key competency for physician learners. This is consistent with the larger trending reform movement in health professions education that emphasizes self-regulation coupled to the development and practice of adaptive mastery [60,61].

\subsection{Limitations}

Our chosen methodology yields rich, insightful data and limitations. The one-onone interviews allowed for insightful exploration of medical students' lived experiences with System 1 and 2 processes during the pre-clerkship phase of their medical education. However, given our abductive approach to data analysis, we must acknowledge that our interpretations may be plausible yet off-target. Participation was limited to first- and second-year medical students who periodically assessed their respective class Facebook groups to be made aware of the opportunity. Students that had previously been exposed to System 1 and System 2 thinking may have been more invested in the topic and inclined to participate. All interviews were conducted by W.S. to foster a more candid dialogue with near-peer participants. Despite explicit statements that all conversations would be kept confidential and information de-identified following interview, it is possible that some students did not disclose relevant experiences to avoid embarrassment or perceived judgement.

\subsection{Future Research}

Future research should follow students longitudinally over their four years in medical school at a variety of institutions to investigate: (1) how their self-regulated strategies for developing pre-clerkship System 1 and System 2 thinking translate to and adapt within the more clinically-relevant clerkship learning environment, and (2) how well equipped and prepared they are, at the conclusion of their undergraduate medical education, for System 1- and System 2-informed practice in residency.

\section{Conclusions}

Most people consider themselves able to discern accurately, reliably, and safely when to trust their instincts and intuition, and when they should pause, reflect, and reason carefully, but often that confidently held belief is undue and irrational. Physician experts strive to adapt back and forth readily from intuitive-based System 1 to analytical-based System 2 thinking, according to the clinical needs and context before them. We sought to understand better how pre-clerkship medical students experience and perceive System 1 and System 2 thinking. Our participants experienced early development of intuitiveand analytical-based cognition, relevant to future clinical performance, in the absence of routine, formal feedback and coaching. Our findings have implications for curricular design, selection of education strategies, as well as mentoring, coaching, and helpful feedback opportunities. This research adds an early physician learner voice to further ongoing conversations about the positioning of these cognitive operations, as well as self-regulation and metacognition, in undergraduate medical education. 
Author Contributions: Conceptualization, W.S. and D.M.; methodology, W.S. and D.M.; formal analysis, W.S. and D.M.; investigation, W.S.; resources, D.M.; data curation, D.M.; writing-original draft preparation, W.S. and D.M.; writing-review and editing, W.S. and D.M.; visualization, D.M.; supervision, D.M.; project administration, W.S. and D.M. All authors have read and agreed to the published version of the manuscript.

Funding: This research received no external funding.

Institutional Review Board Statement: This study was conducted according to the guidelines of the Declaration of Helsinki and approved by the Human Experimentation Committee/Institutional Review Board of Quinnipiac University (\#08818; 17 May 2018).

Informed Consent Statement: Informed consent was obtained from all subjects involved in this study.

Data Availability Statement: The data presented in this study are available on request from the corresponding author. The data are not publicly available in order to maintain participant confidentiality per IRB protocol.

Conflicts of Interest: The authors declare no conflict of interest.

\section{Appendix A}

Pre-Interview Guide

Stanovich and West (2000)'s model of dual-process theory describes two mental processes called System 1 and System 2 (Aragón 2017) [54].

- "System 1 is the fast, automatic, emotional, subconscious process that drives intuitive decisions." (Aragón 2017) [54];

- "System 2 is the slow, reflective, rational, conscious process that enables deliberative decisions." (Aragón 2017) [54].

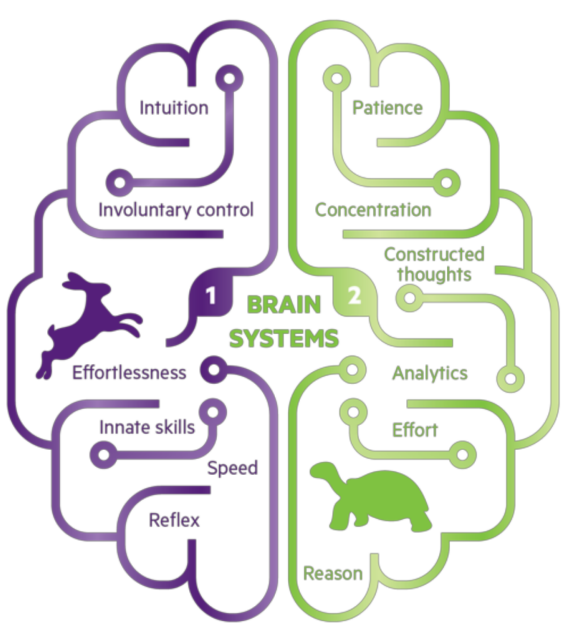

Figure A1. Illustration of the characteristics ascribed to System 1 and System 2 thinking. Image source: Land, 2018 [62].

\section{Appendix B}

\section{Interview Questions}

Tell me about your awareness and understanding of System 1 and System 2 thinking before this interview.

- $\quad$ how would you explain them to someone who hadn't heard of them before?

Are these two modes of thinking important and applicable in your future careers as physicians?

- can you talk me through examples of when you have had to use these skills already? 
- what were the outcomes?

- what other pre-clerkship opportunities exist to use these different types of thinking processes at the Frank H. Netter MD School of Medicine?

When thinking about your medical school experiences, how and when do you think and make decisions quickly?

- can you talk me through an example?

- $\quad$ what about when learning situations or responding to questions?

- how often do trust your first instinct or intuition?

- $\quad$ how often do you revise these decisions? why or why not?

- $\quad$ same question, but how and when do you make decisions slowly?

When thinking about your medical school experiences, how and when do you think and make decisions slowly?

- can you talk me through an example?

- $\quad$ what have been the outcomes when implementing System 2 thinking?

How applicable is it to utilize System 1 and System 2 thinking in your own free time or actions outside of school?

How easy is it for you to pay attention to information that is present, rather than the information that is lacking?

What is your opinion on how emotions affect your ability to think or answer questions?

Have there been any circumstances or factors that have enhanced your ability to transition in the moment between these thinking systems? What makes you believe that?

Have there been any circumstances or factors that have hindered your ability to transition in the moment between these thinking systems? What makes you believe that?

How does being in a group affect your thinking processes?

Did you have any experiences prior to medical school where you encountered these thinking modes? Tell me about them.

Have you noticed any time in which you or your peers made a mistake because of System 1 or System 2 thinking? Can you talk me through an example? How could you tell?

\section{References}

1. Cutrer, W.B.; Sullivan, W.M.; Fleming, A.E. Educational strategies for improving clinical reasoning. Curr. Probl. Pediatric Adolesc. Health Care 2013, 43, 248-257. [CrossRef] [PubMed]

2. Rencic, J.; Durning, S.; Holmboe, E.; Gruppen, L.D. Assessing competence in professional performance across disciplines and professions. In Innovation and Change in Professional Education; Wimmers, P.F., Mentkowski, M., Eds.; Springer International Publishing: Cham, Switzerland, 2016.

3. Kelman, M. The Heuristics Debate; Oxford University Press: New York, NY, USA, 2011.

4. Croskerry, P. Clinical cognition and diagnostic error: Applications of a dual process model of reasoning. Adv. Health Sci. Educ. 2009, 14, 27-35. [CrossRef] [PubMed]

5. Stanovich, K.E. Who is Rational? Studies of Individual Differences in Reasoning; Lawrence Elrbaum Associates: Mahwah, NJ, USA, 1999.

6. Stanovich, K.E.; West, R.F. Individual differences in reasoning: Implications for the rationality debate? Heuristics Biases 2002, 39, 421-440. [CrossRef]

7. Evans, J.S.B.T. In two minds: Dual-process accounts of reasoning. Trends Cogn. Sci. 2003, 7, 454-459. [CrossRef]

8. Hogarth, R.M. Educating Intuition; University of Chicago Press: Chicago, IL, USA, 2001.

9. Hogarth, R.M. Deciding analytically or trusting your intuition? The advantages and disadvantages of analytic and intuitive thought. In Routines of Decision Making; Betsch, T., Haberstroh, S., Eds.; Lawrence Elrbaum Associates: Mahwah, NJ, USA, 2005; pp. 67-82.

10. Croskerry, P. Context is everything or how could I have been that stupid? Health Q. 2009, 12, e171-e176. [CrossRef] [PubMed]

11. Croskerry, P. A universal model of diagnostic reasoning. Acad. Med. 2009, 84, 1022-1028. [CrossRef]

12. Rotgans, J.I.; Schmidt, H.G.; Rosby, L.V.; Tan, G.J.S.; Mamede, S.; Zwaan, L.; Low-Beer, N. Evidence supporting dual-process theory of medical diagnosis: A functional near-infrared spectroscopy study. Med. Educ. 2019, 53, 143-152. [CrossRef]

13. Moulton, C.-A.; Regehr, G.; Mylopoulos, M.; Macrae, H.M. Slowing down when you should: A new model of expert judgment. Acad. Med. 2007, 82, S109-S116. [CrossRef]

14. Croskerry, P. Critical thinking and reasoning in emergency medicine. In Patient Safety in Emergency Medicine; Croskerry, P., Cosby, K.S., Schenkel, S.M., Wears, R.L., Eds.; Lippincott Williams \& Wilkins: Philadelphia, PA, USA, 2008 ; pp. $213-218$. 
15. Ericsson, K.A. Deliberate practice and the acquisition and maintenance of expert performance in medicine and related domains. Acad. Med. 2004, 79, S70-S81. [CrossRef]

16. Choudhry, N.K.; Fletcher, R.H.; Soumerai, S.B. Systematic review: The relationship between clinical experience and quality of health care. Ann. Intern. Med. 2005, 142, 260-273. [CrossRef]

17. Tay, S.W.; Ryan, P.; Ryan, A. Systems 1 and 2 thinking processes and cognitive reflection testing in medical students. Can. Med. Educ. J. 2016, 7, e97-e103. [CrossRef] [PubMed]

18. Quirk, M. Intuition and metacognition in medical education: Keys to developing expertise. In Springer Series on Medical Education; Springer Publishing Company: New York, NY, USA, 2006.

19. Blumenthal-Barby, J.S.; Krieger, H. Cognitive biases and heuristics in medical decision making: A critical review using a systematic search strategy. Med. Decis. Mak. 2015, 35, 539-557. [CrossRef] [PubMed]

20. Sinkovics, R.R.; Alfoldi, E.A. Progressive focusing and trustworthiness in qualitative research: The enabling role of computerassisted qualitative data analysis software (CAQDAS). Manag. Int. Rev. 2012, 52, 817-845. [CrossRef]

21. Parlett, M.; Hamilton, D. Evaluation as illumination: A new approach to the study of innovative programmes. In Evaluation Studies Review Annual; Glass, G., Ed.; Sage: Beverley Hills, CA, USA, 1976; pp. 140-157.

22. Bringer, J.D.; Johnston, L.H.; Brackenridge, C.H. Maximizing transparency in a doctoral thesis: The complexities of writing about the use of QSR*NVIVO within a grounded theory study. Qual. Res. 2004, 4, 247-265. [CrossRef]

23. Locke, K.; Golden-Biddle, K.; Feldman, M.S. Perspective-Making doubt generative: Rethinking the role of doubt in the research process. Organ. Sci. 2008, 19, 907-918. [CrossRef]

24. King, N. Doing template analysis. In Qualitative Methods and Analysis in Organizational Research; Symon, G., Cassell, C., Eds.; Sage: London, UK, 2012; pp. 426-450.

25. Lincoln, Y.; Guba, E. Naturalistic Inquiry; SAGE Publications Ltd.: London, UK, 1985.

26. Langdridge, D. Phenomenological Psychology: Theory, Research and Method; Pearson Education: London, UK, 2007.

27. Onwuegbuzie, A.J.; Combs, J.P. Emergent data analysis techniques in mixed methods research-A synthesis. In SAGE Handbook of Mixed Methods in Social \& Behavioural Research; Tashakkori, A., Teddlie, C., Eds.; SAGE Publications: Thousand Oaks, CA, USA, 2010; pp. 397-430.

28. Butler-Kisber, L. Constant comparison inquiry. In Qualitative Inquiry; Butler-Kisber, L., Ed.; SAGE Publications Ltd.: London, UK, 2018; pp. 41-59.

29. Browncoat, J. Pimping. Urban Dictionary. 2006. Available online: https://www.urbandictionary.com/define.php?term=pimping (accessed on 15 August 2020).

30. Van Merriënboer, J.J.G.; Kester, L.; Paas, F. Teaching complex rather than simple tasks: Balancing intrinsic and germane load to enhance transfer of learning. Appl. Cogn. Psychol. 2006, 20, 343-352. [CrossRef]

31. Mizuno, K.; Tanaka, M.; Yamaguti, K.; Kajimoto, O.; Kuratsune, H.; Watanabe, Y. Mental fatigue caused by prolonged cognitive load associated with sympathetic hyperactivity. Behav. Brain Funct. 2011, 7, 17. [CrossRef]

32. Van Merriënboer, J.; Sweller, J. Cognitive load theory in health professional education: Design principles and strategies. Med. Educ. 2010, 44, 85-93. [CrossRef]

33. Cleary, T.J.; Durning, S.J.; Gruppen, L.D.; Hemmer, P.; Artino, A.R. Self-regulated learning in medical education. In Oxford Textbook of Medical Education; Walsh, K., Ed.; Oxford University Press: Oxford, UK, 2013.

34. Young, J.Q.; Van Merrienboer, J.; Durning, S.; Cate, O.T. Cognitive Load Theory: Implications for medical education: AMEE Guide No. 86. Med. Teach. 2014, 36, 371-384. [CrossRef]

35. Gandomkar, R.; Mirzazadeh, A.; Jalili, M.; Yazdani, K.; Fata, L.; Sandars, J. Self-regulated learning processes of medical students during an academic learning task. Med. Educ. 2016, 50, 1065-1074. [CrossRef]

36. Leppink, J.; Duvivier, R. Twelve tips for medical curriculum design from a cognitive load theory perspective. Med. Teach. 2016, 38, 669-674. [CrossRef] [PubMed]

37. Sewell, J.L.; Maggio, L.A.; Cate, O.T.; Van Gog, T.; Young, J.Q.; O'Sullivan, P.S. Cognitive load theory for training health professionals in the workplace: A BEME review of studies among diverse professions: BEME Guide No. 53. Med. Teach. 2019, 41, 256-270. [CrossRef] [PubMed]

38. Zheng, B.; Ward, A.; Stanulis, R. Self-regulated learning in a competency-based and flipped learning environment: Learning strategies across achievement levels and years. Med. Educ. Online 2020, 25, 1686949. [CrossRef] [PubMed]

39. Zimmerman, B.J. Investigating self-regulation and motivation: Historical background, methodological developments, and future prospects. Am. Educ. Res. J. 2008, 45, 166-183. [CrossRef]

40. Sweller, J. Cognitive load during problem solving: Effects on learning. Cogn. Sci. 1988, 12, 257-285. [CrossRef]

41. Mayer, R.E.; Moreno, R. Nine ways to reduce cognitive load in multimedia learning. Educ. Psychol. 2003, 38, 43-52. [CrossRef]

42. Shunk, D. Goal and self-evaluative influences during children's cognitive skill learning. Am. Educ. Res. J. 1996, 33, 359-382. [CrossRef]

43. Harris, K.R.; Graham, S. Programmatic intervention research: Illustrations from the evolution of self-regulated strategy development. Learn. Disabil. Q. 1999, 22, 251-262. [CrossRef]

44. Schraw, G.; Crippen, K.J.; Hartley, K. Promoting self-regulation in science education: Metacognition as part of a broader perspective on learning. Res. Sci. Educ. 2006, 36, 111-139. [CrossRef]

45. Kirschner, F.; Paas, F.; Kirschner, P.A. A cognitive load approach to collaborative learning: United brains for complex tasks. Educ. Psychol. Rev. 2009, 21, 31-42. [CrossRef] 
46. Zimmerman, B.J. Development and adaptation of expertise: The role of self-regulatory processes and beliefs. In The Cambridge Handbook of Expertise and Expert Performance; Ericsson, K.A., Charness, N., Feltovich, P.J., Hoffman, R.R., Eds.; Cambridge University Press: New York, NY, USA, 2006; pp. 705-723.

47. Issenberg, S.B.; McGaghie, W.C.; Petrusa, E.R.; Lee, G.D.; Scalese, R.J. Features and uses of high-fidelity medical simulations that lead to effective learning: A BEME systematic review. Med. Teach. 2005, 27, 10-28. [CrossRef] [PubMed]

48. Karpicke, J.D.; Blunt, J.R. Retrieval practice produces more learning than elaborative studying with concept mapping. Science 2011, 331, 772-775. [CrossRef] [PubMed]

49. McDaniel, M.A.; Wildman, K.M.; Anderson, J.L. Using quizzes to enhance summative-assessment performance in a web-based class: An experimental study. J. Appl. Res. Mem. Cogn. 2012, 1, 18-26. [CrossRef]

50. Rosby, L.V.; Rotgans, J.I.; Tan, G.; Low-Beer, N.; Mamede, S.; Zwaan, L.; Schmidt, H. Inducing System-1-type diagnostic reasoning in second-year medical students within $15 \mathrm{~min}$. Med. Teach. 2018, 40, 1030-1035. [CrossRef]

51. Simpson, D.; Hamilton-Shield, A.; Giza, M.; Baker, J. Comment on: Inducing system-1-type diagnostic reasoning in second-year medical students within $15 \mathrm{~min}$. Med. Teach. 2019, 41, 483. [CrossRef]

52. Lee, C.S.; Nagy, P.G.; Weaver, S.J.; Newman-Toker, D.E. Cognitive and system factors contributing to diagnostic errors in radiology. Am. J. Roentgenol. 2013, 201, 611-617. [CrossRef]

53. Furnham, A.; Boo, H.C. A literature review of the anchoring effect. J. Socio-Econ. 2011, 40, 35-42. [CrossRef]

54. Aragón, T.J. How You Actually Make Decisions Will Surprise You. 2017. Available online: https://taragonmd.github.io/2017/1 2/08/how-you-actually-make-decisions-will-surprise-you/ (accessed on 15 August 2020).

55. Kahneman, D.; Tversky, A. Subjective probability: A judgment of representativeness. Cogn. Psychol. 1972, 3, 430-454. [CrossRef]

56. Tversky, A.; Kahneman, D. Availability: A heuristic for judging frequency and probability. Cogn. Psychol. 1973, 5, 207-232. [CrossRef]

57. Taylor, S.E. The interface of cognitive and social psychology. In Cognition, Social Behavior, and the Environment; Harvey, J.H., Ed.; Lawrence Erlbaum Associates Inc.: Hillsdale, NJ, USA, 1981; pp. 189-211.

58. Lefroy, J.; Watling, C.; Teunissen, P.W.; Brand, P. Guidelines: The do's, don'ts and don't knows of feedback for clinical education. Perspect. Med. Educ. 2015, 4, 284-299. [CrossRef]

59. Association of American Medical Colleges. Recommendations for Preclerkship Clinical Skills Education for Under-graduate Medical Education. Task Force on the Clinical Skills Education of Medical Students. 2008. Available online: https://paeaonline. org/wp-content/uploads/2016/07/7a-Clinical-Skills-Education.pdf (accessed on 16 July 2020).

60. Panadero, E. A Review of Self-regulated Learning: Six Models and Four Directions for Research. Front. Psychol. $2017,8,422$. Available online: https:/ / www.ncbi.nlm.nih.gov/pmc/articles/PMC5408091/ (accessed on 18 July 2020).

61. Cutrer, W.B.; Miller, B.; Pusic, M.V.; Mejicano, G.; Mangrulkar, R.S.; Gruppen, L.D.; Hawkins, R.E.; Skochelak, S.E.; Moore, D.E., Jr. Fostering the development of master adaptive learners: A conceptual model to guide skill acquisition in medical education. Acad. Med. 2017, 92, 70-75. [CrossRef] [PubMed]

62. Land, S. Illustration of the Characteristics Ascribed to System 1 and System 2 Thinking. 2018. Available online: https://siimland. com/thinking-fast-and-slow-explained/ (accessed on 15 December 2020). 